\title{
Work-related ill health in doctors working in Great Britain: incidence rates and trends
}

Anli Yue Zhou, Melanie Carder, Matthew Gittins and Raymond Agius

\section{Background}

Doctors have a higher prevalence of mental ill health compared with other professional occupations but incidence rates are poorly studied.

\section{Aims}

To determine incidence rates and trends of work-related ill health $(\mathrm{WRIH})$ and work-related mental ill health $(\mathrm{WRMIH})$ in doctors compared with other professions in Great Britain.

\section{Method}

Incidence rates were calculated using an occupational physician reporting scheme from 2005-2010. Multileve regression was use to study incidence rates from 2001 to 2014

\section{Results}

Annual incidence rates for WRIH and WRIMH in doctors were 515 and 431 per 100000 people employed, respectively.
Higher incidence rates for WRIH and WRMIH were observed for ambulance staff and nurses, respectively. Doctors demonstrated an annual average incidence rates increase for WRIH and WRMIH, especially in women, whereas the other occupations demonstrated a decreasing or static trend. The difference in trends between the occupations was statistically significant.

\section{Conclusions}

WRIH and WRMIH incidence rate are increasing in doctors, especially in women, warranting further research.

\section{Declaration of interest}

None.

\section{Copyright and usage}

(c) The Royal College of Psychiatrists 2017.
The National Health Service (NHS) is one of the largest employers in the UK with the healthcare sector having one of the highest sickness absence rates in comparison with other industries. ${ }^{1}$ There have been concerns regarding increasing demands, and constraints on resources and staffing within the NHS. ${ }^{2}$ Doctors have reported feeling increasingly stressed, which could be caused by increasing workloads, poor morale and staff shortages. ${ }^{2} \mathrm{~A}$ higher prevalence of occupational stress and mental ill health has been reported in doctors in comparison with other professions such as teachers, accountants and health service managers. ${ }^{3-8}$ Other studies have demonstrated that doctors tend to take less sickness absence in comparison with other professions such as nurses, despite having similar health statuses. ${ }^{3,5,9}$ This could be because of increased 'sickness presenteeism', commitment to work and inadequate staff cover. ${ }^{3,5}$ Although previous studies have explored the prevalence of stress and mental ill health in doctors, ${ }^{4,7,10-17}$ there have not been any studies investigating whether incidence and trends in incidence of work-related mental ill health (WRMIH) in doctors working in Great Britain is increasing. Incidence rates and trends in incidence rates can be used to estimate risk, whereas prevalence studies can only estimate the current burden of disease. A previous study of trends in work-related ill health (WRIH) incidence using occupational physicians' reported incidence data has shown that the reported incidence of WRMIH has been increasing over recent years in the health and social care sector. ${ }^{18}$ Moreover, it is not known whether the trend in incidence of WRIH and WRMIH in doctors is similar to other public service occupations such as nurses, ambulance staff, social workers and teachers. The aim of this study was therefore to estimate and then compare the incidence and time trends in incidence of WRIH and WRMIH in doctors with other public service professions (nurses, social workers, ambulance staff and teachers). For the purpose of this study, WRIH cases include all cases of ill health that are caused or aggravated by work, which will include WRMIH cases too. WRMIH cases will only include cases of mental ill health that are caused or aggravated by work. This is therefore a subset of WRIH.

\section{Method}

The Health and Occupation Research (THOR) Network is the only UK-wide medically diagnosed data source of individual incident case reports of all WRIH. ${ }^{19}$ THOR consists of a number of physician-reported surveillance schemes for WRIH, through which participating clinical consultants, occupational physicians and general practitioners (GPs) report incident cases of WRIH seen during their usual clinical practice. ${ }^{19}$ One of the surveillance schemes within the THOR network is Occupational Physicians Reporting Activity (OPRA), which collects data on occupational-physician-reported incident cases of WRIH. There is good occupational physician coverage in the health and social care sector by OPRA reporters ${ }^{20}$ and therefore OPRA as a data source can provide accurate estimations of incidence and trends in incidence for workers within this sector.

The methods used in THOR and OPRA have been documented previously. ${ }^{18,21}$ In brief, reporting physicians are asked to report newly diagnosed (i.e. incident) cases of WRIH and which they judge to have been caused or aggravated by work. For each case, the occupational physician is asked to report the diagnosis, age, gender, occupation, industry, suspected agent (the hazard/agent causing or contributing to WRIH), reason for referral to an occupational physician and date of symptom onset. The reported cases provide the numerator data to estimate incidence and trends in incidence. Information on occupation is subsequently classified using the Standard Occupation Classification 2000 (SOC 2000). ${ }^{22}$ Physicians participate in OPRA on either a continuous monthly basis ('core' reporting) or for one randomly selected month each year ('sample' reporting) to avoid seasonal bias. Sample reporting was used to reduce the burden and fatigue of reporting. Annual 
estimated cases were calculated by multiplying the cases reported by 'sample' reporters by 12 and then adding them to the cases reported by core reporters.

Case reports in Great Britain for the group of interest (doctors) and the comparison groups (nurses, social workers, ambulance staff and teachers) were extracted from the OPRA database for the period 2001 to 2014. This enabled comparisons of doctors to be made with other selected public sector occupations working in education and healthcare. Furthermore, teachers were in the same SOC classification as doctors. This means that both occupations are in the same category based on skill level and skill content. ${ }^{22}$ The chi-squared test was used to compare the gender distribution of the reported cases compared with the population using the Labour Force Survey data (LFS) ${ }^{23}$ across each of the occupations.

\section{Calculating incidence rates}

As a result of the uneven access to occupational physicians across Great Britain, it is estimated that only $12 \%$ of the workforce have access to an occupational physician. ${ }^{20}$ However, there is disproportionate occupational physician coverage between different industry sectors, with public sectors and larger employers having better coverage in comparison with other industries such as agriculture. ${ }^{20}$ Hence, applying the total workforce calculated from the $\mathrm{LFS}^{23}$ as the denominator could lead to inaccurate incidence rates. In order to improve the quality of the underlying denominator, a 3-year rolling denominator survey was initiated to investigate the workforce covered by OPRA reporters. ${ }^{20}$ The type of workforce that occupational physician reporters covered was classified according to major industries using the Standard Industrial Classification (SIC) 2003 and 2007. ${ }^{24}$ This was done for two triennia: 2005-2007 and 2008-2010. The numerator was the annual average number of estimated cases reported to OPRA (in each triennium). Cases of interest were initially identified by industry (health and social care sector, education sector) and by occupation (doctors, nurses, social workers, ambulance staff and teachers). Cases were only included if the occupational physician who reported them had provided denominator information (in one or both of the occupational physician denominator surveys) for the industry from which the cases arose. Incidence rates by industry (health and social care or education) were calculated by applying the number of people employed in each sector according to the occupational physician denominator surveys (2005-2007 or 2008-2010) as the denominator. To calculate incident rates by occupation, the denominator of the industry covered by the occupational physician were adjusted according to the proportion of an occupation within an industry. The proportion of an occupation within an industry was calculated using the LFS data. A flow chart summarising how incidence rates were calculated is shown in Fig. 1.

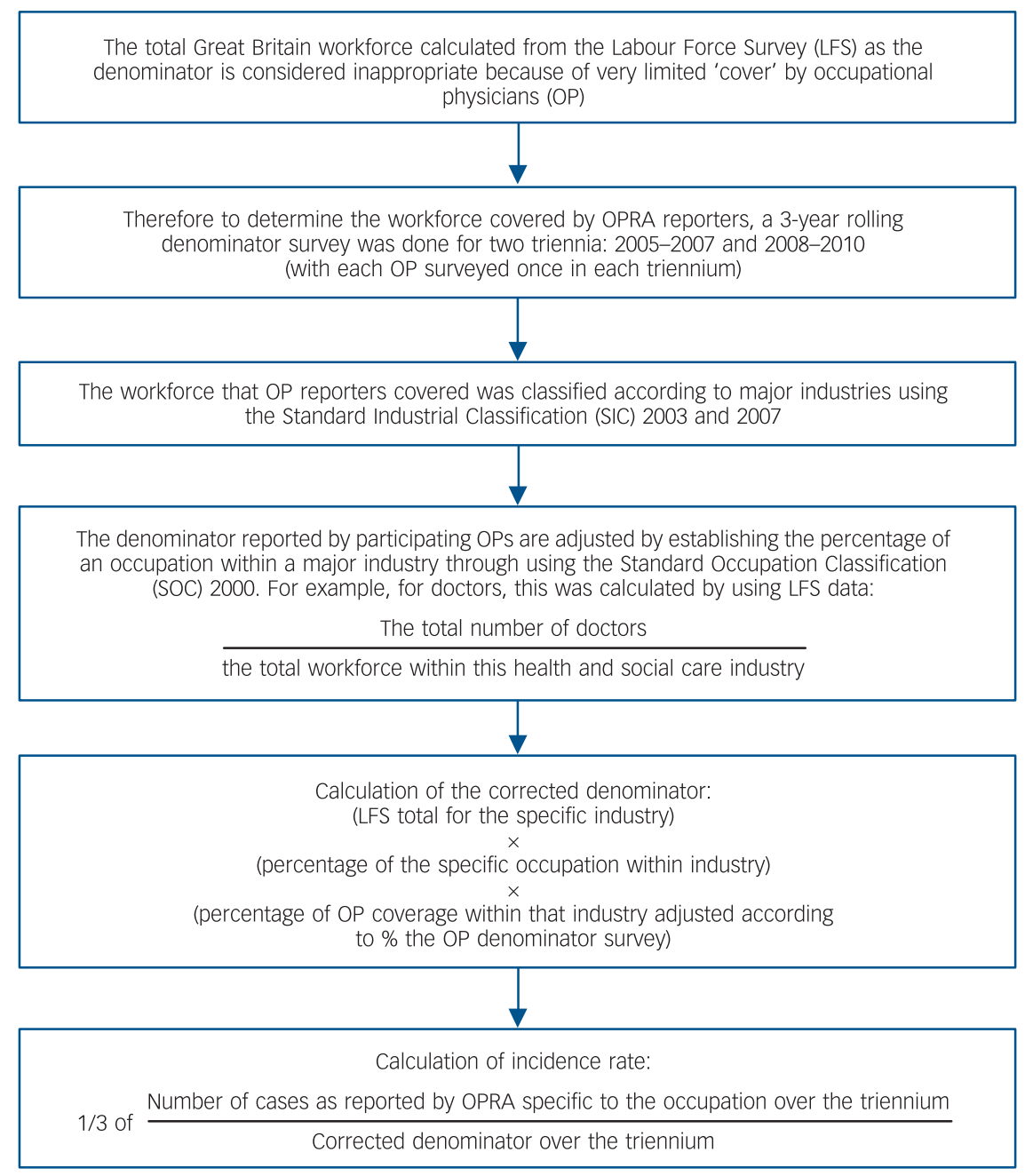

Fig. 1 Flow chart summarising the methods used to calculate incidence rates. 
To calculate the confidence intervals for incidence rates, a normal approximation to the Poisson distribution was assumed and complex sample survey methodology employed in the form of a first-order Taylor linearised variance estimator. ${ }^{25}$

\section{Time trends analyses}

The methods used to analyse trends in WRIH and WRMIH incidence based on data from the THOR surveillance scheme have been described previously. ${ }^{18,26}$ In brief, estimated changes in incidence across calendar time (2001-2014) were investigated using multilevel longitudinal, negative binomial models with random repetitive effects. This method accounts for within- and between-reporter variation in responses because of clustering, i.e. 12 responses per year for core reporters and 1 per year for sample reporters. ${ }^{26}$ The dependent variable was the number of reported cases per reporter per month (which includes zero responses). The main predictor of interest, mean centred calendar time, was represented as a continuous variable with a scale of years. Variables representing other potential confounders such as season, reporter type (core or sample reporter), first month as new core reporter, membership time, first month as new reporter and industrial group were also included as covariates. ${ }^{26}$ To account for changes in population base, an offset variable representing the number of people employed in Great Britain each year (i.e. 2001-2014) in the occupational group under investigation was included. Finally, to assess whether there were differences in trends between doctors and other occupational groups, a statistical interaction term between occupation group and calendar years was added to the model. All analysis was performed in Stata v14. Multicentre Research Ethics Committee approval has been granted to THOR (reference number MREC 02/8/72).

\section{Results}

\section{Descriptive characteristics and incidence rates}

Between 2005 and 2010, the total number of estimated incident cases from the occupational physician reporting scheme were: doctors 1097, nurses 4946, social workers 433, ambulance staff 268 and teachers 1649 . The percentage proportions of gender mixes found in our results were representative of the gender mix found in these occupations in the population (according to the LFS data). The chi-squared test of distribution showed that the gender proportions found in our results were representative of the working population for doctors, but not for nurses, ambulance staff, social workers and teachers $(P<0.001)$. From 2005-2010, 82.5\% of WRIH cases in doctors were WRMIH. Less than half of WRIH cases in ambulance staff were WRMIH cases, whereas for the other occupations, a significant proportion of WRIH cases $(>60 \%)$ were WRMIH cases (Table 1 ).

Adjusted incidence rates taking account of the corrected denominator for both triennia are shown in Table 1. Incidence rates between the two triennia showed little variation and therefore are presented as an average incidence rate over both, i.e. from 2005 to 2010. Both ambulance staff and nurses indicated a higher incidence of WRIH and WRMIH compared with doctors, which in turn were higher than for teachers and social workers. Overall, higher incidence rates were found in the health and social care sector in comparison with the education sector.

\section{Time trends analyses}

The total number of cases and estimated annual percentage changes for WRIH, WRMIH and WRIH without mental health are presented in Table 2. From 2001 to 2014, a statistically significant increase in WRIH was demonstrated for doctors only, with an annual average increase of $+6.1 \%$ (95\% CI $+2.2 \%$ to $+10.1 \%)$, and similar trends for both female and male doctors (Table 2). For nurses, ambulance staff and teachers, all three occupations showed an annual average decrease in incidence of $-3.2 \% \quad(95 \%$ CI $-5.3 \%$ to $-1.0 \%),-10.8 \% \quad(95 \%$ CI $-18.2 \%$ to $-2.5 \%)$ and $-4.3 \%(95 \%$ CI $-5.3 \%$ to $-1.0 \%)$, respectively with no trend observed in social workers. Statistically significant interaction effects indicated differences in the calendar trend of WRIH in nurses $(P<0.001)$, ambulance staff $(P<0.001)$ and teachers $(P<0.001)$ compared with doctors.

For WRMIH, only doctors showed a statistically significant annual average increase in incidence of $+6.5 \%(95 \%$ CI $+2.2 \%$ to $+11 \%)$. Teachers showed a statistically significant average annual decrease of $-3.9 \%$ ( $95 \%$ CI $-6.5 \%$ to $-1.2 \%$ ). Nurses, ambulance staff and social workers did not show a statistically significant annual average change between 2001 and 2014 .

\begin{tabular}{|c|c|c|c|c|c|c|c|}
\hline \multirow[b]{2}{*}{ Cases of ill health, 2005-2010 } & \multicolumn{5}{|c|}{ Occupation } & \multicolumn{2}{|l|}{ Sector } \\
\hline & Doctors & Nurses & Social workers & Ambulance staff & Teachers & Health and social care & Education \\
\hline \multicolumn{8}{|l|}{ Work-related ill health } \\
\hline Age, years: median & 44 & 44 & 50 & 43 & 49 & - & - \\
\hline Age, years: range & $22-65$ & $18-68$ & $25-64$ & $26-53$ & $22-63$ & - & - \\
\hline Female, $n(\%)$ & $437(40)$ & $4162(84)$ & $305(70)$ & $80(30)$ & $952(58)$ & - & - \\
\hline Male, $n(\%)$ & $660(60)$ & $784(16)$ & $128(30)$ & $188(70)$ & $697(42)$ & - & - \\
\hline Total, $n$ & 1097 & 4946 & 433 & 268 & 1649 & - & - \\
\hline $\begin{array}{l}\text { Incidence rates/100000 } \\
\text { people employed }(95 \% \mathrm{Cl})\end{array}$ & $515(409-621)$ & $964(760-1167)$ & $227(128-327)$ & $1611(306-2917)$ & $228(171-285)$ & $461(378-544)$ & $225(169-281)$ \\
\hline \multicolumn{8}{|l|}{ Work-related mental ill health } \\
\hline Age, years: median & 46 & 45 & 49 & 44 & 50 & - & - \\
\hline Age, years: range & $22-65$ & $22-62$ & $25-64$ & $27-53$ & $25-63$ & - & - \\
\hline Female, $n(\%)$ & $314(35)$ & $2608(83)$ & $276(71)$ & $36(31)$ & $817(56)$ & - & - \\
\hline Male, $n(\%)$ & $591(65)$ & $553(17)$ & $116(30)$ & 79 (69) & $631(44)$ & - & - \\
\hline Total, $n$ & 905 & 3161 & 390 & 115 & 1448 & - & - \\
\hline $\begin{array}{l}\text { Percentage of total cases of } \\
\text { work-related ill health } \\
\text { Incidence rates } / 100000\end{array}$ & 83 & 64 & 90 & 43 & 88 & - & - \\
\hline people employed $(95 \% \mathrm{Cl})$ & $431(335-528)$ & $641(497-785)$ & $221(123-320)$ & $610(0-1313)$ & $201(156-247)$ & $286(235-337)$ & $165(125-205)$ \\
\hline
\end{tabular}




\begin{tabular}{|c|c|c|c|c|c|c|}
\hline \multirow[b]{2}{*}{ Occupation } & \multicolumn{2}{|c|}{ Work-related ill health (WRIH) cases } & \multicolumn{2}{|c|}{$\begin{array}{l}\text { Work-related ill health (WRIH) without } \\
\text { mental health cases }\end{array}$} & \multicolumn{2}{|c|}{$\begin{array}{l}\text { Work-related mental ill health } \\
\text { (WRMIH) cases only }\end{array}$} \\
\hline & $\begin{array}{l}\text { Actual } \\
\text { cases, } n\end{array}$ & $\begin{array}{l}\text { Annual percentage change } \\
\text { in incidence rate }(95 \% \mathrm{Cl})\end{array}$ & $\begin{array}{l}\text { Actual } \\
\text { cases, } n\end{array}$ & $\begin{array}{l}\text { Annual percentage change } \\
\text { in incidence rate }(95 \% \mathrm{Cl})\end{array}$ & $\begin{array}{l}\text { Actual } \\
\text { cases, } n\end{array}$ & $\begin{array}{l}\text { Annual percentage change } \\
\text { in incidence rate }(95 \% \mathrm{Cl})\end{array}$ \\
\hline Doctors & 334 & $+6.1(+2.2$ to +10.1$)$ & 69 & $+1.9(-5.4$ to +9.7$)$ & 265 & $+6.5(+2.2$ to +11$)$ \\
\hline Female & 152 & $+6.4(+0.6$ to +12.5$)$ & 39 & $-2.6(-11.6$ to +7.4$)$ & 113 & $+8.6(+1.7$ to +16.0$)$ \\
\hline Male & 182 & $+5.1(+0.3$ to +10.2$)$ & 30 & $-{ }^{\mathrm{a}}$ & 152 & $+4.4(-0.7$ to +9.9$)$ \\
\hline Nurses & 1617 & $-3.2(-5.3$ to -1.0$)$ & 612 & $-5.7(-8.7$ to -2.7$)$ & 1005 & $-1.3(-4.0$ to +1.4$)$ \\
\hline Female & 1390 & $-3.5(-5.8$ to -1.2$)$ & 544 & $-6.9(-10.0$ to -3.7$)$ & 846 & $+1(-3.8$ to +1.9$)$ \\
\hline Male & 227 & $-2.3(-6.8$ to +2.3$)$ & 68 & $+0.8(-6.4$ to +8.5$)$ & 159 & $-4.3(-9.6$ to +1.3$)$ \\
\hline Social workers & 209 & $0(-4.8$ to +5.9$)$ & 18 & $-^{\mathrm{a}}$ & 191 & $1.2(-4.3$ to +7.0$)$ \\
\hline Female & 155 & $+2.8(-3.1$ to +9.1$)$ & 16 & $-{ }^{a}$ & 139 & $+3.8(-2.5$ to +10.4$)$ \\
\hline Male & 54 & $-2.6(-11.7$ to +7.4$)$ & 2 & $-{ }^{a}$ & 52 & $-1.8(-11.0$ to +8.4$)$ \\
\hline Ambulance staff & 95 & $-10.8(-18.2$ to -2.5$)$ & 64 & $-10.9(-20$ to -0.9$)$ & 31 & $-4.9(-15.7$ to +7.2$)$ \\
\hline Female & 34 & $-0.3(-12.3$ to +13.3$)$ & 29 & $-3.3(-16.1$ to +11.5$)$ & 5 & $--^{a}$ \\
\hline Male & 61 & $-11.3(-19.8$ to -1.9$)$ & 35 & $-12.4(-13.6$ to 0.0$)$ & 26 & $-^{\mathrm{a}}$ \\
\hline Teachers & 977 & $-4.3(-5.3$ to -1.0$)$ & 101 & $-8.5(-15$ to -1.6$)$ & 876 & $-3.9(-6.5$ to -1.2$)$ \\
\hline Female & 608 & $-3.8(-6.8$ to -0.7$)$ & 78 & $-10.6(-17.9$ to -2.6$)$ & 346 & $-2.6(-5.9$ to +0.7$)$ \\
\hline Male & 369 & $-6.7(-10.3$ to -2.9$)$ & 23 & $-3.4(-14.7$ to +9.4$)$ & 530 & $-6.9(-10.7$ to -3.0$)$ \\
\hline
\end{tabular}

Statistically significant interaction effects indicated differences in the calendar trend of WRMIH in nurses $(P=0.01)$, ambulance staff $(P=0.03)$ and teachers $(P<0.001)$ compared with doctors.

For WRIH without mental ill health cases, an annual average increase in incidence for doctors was not observed. However, for nurses, ambulance staff and teachers, all three groups showed a statistically significant annual average decrease in incidence of $-5.7 \%$ (95\% CI $-8.7 \%$ to $-2.7 \%),-10.9 \%$ (95\% CI $-20 \%$ to $-0.9 \%)$ and $-8.5 \%(95 \% \mathrm{CI}-15 \%$ to $-1.6 \%)$, respectively. Statistically significant interaction effects indicated differences in the calendar trend of WRIH without mental ill health cases in ambulance staff $(P=0.01)$ and teachers $(P=0.05)$ compared with doctors.

\section{Discussion}

\section{Summary of the results}

This study indicated that compared with doctors, incidence rates were highest in ambulance staff for reported WRIH and nurses for reported WRMIH. However, the trends analyses suggested that the incidence of both reported WRIH and WRMIH has been increasing in doctors since 2001, especially in female doctors. On the other hand, other occupations such as ambulance staff, nurses and teachers have largely shown either a decreasing trend or no significant change in incidence since 2001.

\section{Meaning of the results}

Our time trends analyses for WRIH and WRMIH in doctors showed an increase over time whereas other occupations showed a decrease or no significant change in incidence of reported ill health and mental ill health. This could be the result of a number of reasons that may affect doctors more as a profession such as poor training in management skills, work overload in both clinical and non-clinical duties, staff shortages, perceived lack of control and feedback especially when it comes to patient care, high responsibility, lack of support, poor work-life balance and pressures on continuing professional development. ${ }^{2,3,10,11,13,14,16,27}$ Although some of the above reasons may not be exclusive to doctors, it is likely that multiple factors would be occurring simultaneously in doctors who have ultimate responsibility for clinical care, which in turn is more likely to have an impact on their well-being. The above reasons are supported by a recent systematic meta-review that has identified three broad work-related factors that could contribute to the development of common mental health conditions such as depression and anxiety: unsuitable job designs, job uncertainty and lack of workplace value and respect. ${ }^{28}$ These factors could also be relevant to WRMIH in the medical profession and our data show that out of 1944 precipitating events from 2001 to 2014 , the most common ones were workload $(29 \%, n=572)$ (unsuitable job design), work stress $(14 \%, n=267)$ (unsuitable job design) and organisation factors such as poor management, poor role and low job control and perceived lack of support (9\%, $n=167$ ) (job uncertainty and lack of workplace value and respect).

Within our analysis, female doctors showed a statistically significant annual average increase in WRMIH over time. There has been discussion within the literature suggesting that women are more susceptible to stress and depression. ${ }^{29}$ This could be because female doctors may be more likely to experience conflicts between their career and personal commitments which in turn, could more likely have an impact on their work-life balance and mental well-being compared with men. ${ }^{27,29,30}$ The subsequent effects of WRMIH in both genders could lead to increased sickness absence, substance misuse and negative effects on work performance, morale and relations with patients. ${ }^{2,15,31,32}$ Furthermore, WRMIH has been associated with perceived lower standards of care as well as lower performance standards. ${ }^{32}$

Although doctors were not found to have the highest incidence rate of WRIH and WRMIH, previous studies suggest that doctors may be reluctant to access help even though there are formal support systems within the NHS and through charities. ${ }^{33}$ This could suggest that our results may be an underestimation of the extent of WRIH and WRMIH in doctors. Even at early stages of their career, medical students have already shown a preference to seek informal help from family and friends rather than to access formal support systems. ${ }^{34}$ Furthermore, it is possible that a significant proportion of doctors who are referred to occupational physicians may avoid discussing the extent of their problem ${ }^{33}$ and underestimate the actual severity of the impact on their well-being. Adams et al showed that despite the 
high prevalence of depression in doctors within their study, only a small proportion of doctors took sickness absence for their mental health and those doctors with depression were more likely to take time off for a physical problem rather than for their depression. ${ }^{35}$ Many doctors were still reluctant to disclose mental health problems, citing career implications, professional integrity and stigmatisation as the main barriers to disclosure, and there was a strong preference to be treated in a private institution for their mental ill health. ${ }^{36}$ Sadly, over $40 \%$ of those surveyed still preferred to have informal advice as their first treatment preference, ${ }^{36}$ suggesting that the increasing trend of WRMIH diagnoses between 2001 and 2014, as reported by occupational physicians within our study could be underestimated because of underreporting.

Within our study, occupations such as nurses, ambulance staff and teachers showed a decrease in average annual incidence for non-WRMIH. Johnson et al found that ambulance staff and teachers self-reported the lowest physical health compared with other professions, which included doctors. ${ }^{7}$ Furthermore, manual handling injuries are not uncommon in nursing staff. ${ }^{37}$ The manual nature of these jobs may have initially led to higher incidence rates of WRIH and non-WRMIH cases within the OPRA scheme compared with doctors. However, the decrease in average annual incidence rate may have been contributed by the introduction of legislation, intervention and greater awareness on preventing physical injuries in the workplace. ${ }^{37}$

\section{Strengths and limitations}

To our knowledge, this is the first study that has investigated the trend in incidence of WRIH and WRMIH in doctors. Although other studies have demonstrated the extent of mental ill health in doctors, those studies examined prevalence rather than incidence and trends in incidence. ${ }^{4,5,7,10-13,16,17,29}$ The present surveillance-based study, besides estimating incidence rates of WRMIH in doctors, also enables comparisons with different occupations of both incidence rates and trends of incidence rates. Self-reported data of WRIH and WRMIH could be biased by attitudes and beliefs as well as underreporting, therefore making it difficult to reliably assess the actual extent of WRIH and WRMIH among doctors. In contrast, our study used data reported by physicians seeing the doctors in which incidence rates and trends in incidence rates can be used to estimate risk, whereas prevalence studies can only estimate the burden of disease. Data collected by occupational disease surveillance systems such as OPRA contribute to national statistics and identify changes in incidence over time. ${ }^{38,39}$ In turn, this can provide evidence to guide further research that can potentially influence policy at a government level so that interventions and services can be targeted to improve managing WRIH and WRIMIH in doctors.

One limitation of the denominator survey was that the occupational physician denominator surveys only covered two triennia reducing the sample size available. Moreover, denominator estimation could be subject to recall bias and generalisations because of potential difficulties in accurately defining the workforce they cover. ${ }^{20}$ Furthermore, it could be possible that non-responder bias was present, as not all OPRA reporters participated in the denominator survey in both triennia. To calculate incidence rates by occupation, the industry denominators were adjusted by the proportion of an occupation within an industry, according to the LFS. However, the workforce coverage by the individual occupational physicians may not be representative of the proportion within an industry as found in the LFS data because of the case mix that occupational physicians review. This could lead to overestimation if occupational physicians see a higher proportion of a certain occupation or underestimation of incidence rates if occupational physicians review a lower proportion of another occupation. Nevertheless, by using the data from the denominator surveys, this enables the incidence rates of WRIH to be calculated more accurately than using LFS as the denominator and results could therefore be generalised and triangulated with other data sources, both within and external to THOR. ${ }^{18,20}$

This study has presented both 'unadjusted' and 'adjusted' incidence rates, with the latter adjusting the numerator to allow for cases not captured as a result of non-participation and nonresponse. ${ }^{21}$ Furthermore, random selection of sample reporters' 1-month reporting period can minimise seasonal bias. This approach might overestimate rates as it assumes that physicians not participating/responding would report (on average) at the same density as those that are. However, even with these adjustments, given the difficulty of work attribution for mental ill health diagnoses, it is possible that the adjusted rates underestimate the true incidence of WRMIH in Britain. Further methodological assumptions regarding sampling frequency or estimation of denominators may also have led to rates being under- or overestimated. Although not directly addressed in the current study, the sensitivity of incidence rate calculations to these assumptions has been extensively addressed previously in the THOR data-set. ${ }^{20,21,40}$

Another limitation of the present study is that because of the constraints of the data collection, it was not possible to differentiate between the grade and specialty of the doctors. Certain specialties such as accident and emergency, psychiatry and general practice have been shown to have higher prevalence of mental ill health compared with other specialties. ${ }^{4,11,12,14,29}$ However, even if our data were able to differentiate between grade and specialty, trends analyses may not have been possible because of small numbers of cases within each subgroup. Furthermore, as a result of limitations in the type of data collected, we were not able to investigate sickness absence rates or health-seeking behaviours that could have complimented our results.

\section{Suggestions for future research}

This study shows that the incidence of WRIH and WRMIH is increasing in doctors as reported by occupational physicians, especially in female doctors, whereas the other compared occupations largely showed either a decreasing trend or no significant change since 2001. Further research is required to explore the underlying factors contributing to this finding in order to identify modifiable factors. By identifying the underlying contributing factors, research can then be tailored to investigate and assess interventions that optimise the management of both WRIH and WRMIH in doctors. This in turn could contribute to improving and maintaining excellent patient care and safety in the long term.

Anli Yue Zhou, MBChB, MA, MRCP, Melanie Carder, PhD, Centre for Occupational and Environmental Health, Centre for Epidemiology, Division of Population Health, School of Health Sciences, Faculty of Biology, Medicine and Health, The University of Manchester, Manchester; Matthew Gittins, PhD, Centre for Biostatistics, Centre for Epidemiology, Division of Population Health, School of Health Sciences, Faculty of Biology, Medicine and Health, The University of Manchester, Manchester; Raymond Agius, MD, DM, FRCP, FRCPE, FFOM, Centre for Occupational and Environmental Agius, MD, DM, FRCP, FRCPE, FFOM, Centre for Occupational and Environmenta
Health, Centre for Epidemiology, Division of Population Health, School of Health Sciences, Faculty of Biology, Medicine and Health, The University of Manchester, Manchester, UK

Correspondence: Anli Yue Zhou, Room C4.21, Level 4, C block, Centre for Occupational and Environmental Health, Ellen Wilkinson Building, Oxford Road, Manchester M13 9PL, UK. Email: yue.zhou@postgrad.manchester.ac.uk

First received 13 Apr 2017, final revision 13 Jul 2017, accepted 14 Jul 2017 


\section{Funding}

THOR in the UK is largely funded by the Health and Safety Executive (HSE). The opinions in this paper are those of the authors and not of the funders. The funders did not contribute to this study. The funders had no role in study design, data collection, data interpretation, writing report or decision to submit the article for publication.

\section{Acknowledgements}

The authors would like to thank all the doctors who participate in the OPRA surveillance scheme. We would like to thank the Health and Safety Executive (HSE) for partially funding the OPRA surveillance scheme.

\section{References}

1 Office for National Statistics. Sickness Absence in the Labour Market: February 2014. ONS, 2014 (http://www.ons.gov.uk/ons/rel/lmac/sicknessabsence-in-the-labour-market/2014/rpt—sickness-absence-in-the-labourmarket.html).

2 Royal College of Physicians. Underfunded, Underdoctored, Overstretched: The NHS in 2016. Royal College of Physicians, 2016 (https:// www.rcplondon.ac.uk/guidelines-policy/underfunded-underdoctored-overstretched-nhs-2016)

3 McKevitt C, Morgan M, Dundas R, Holland W. Sickness absence and 'working through' illness: a comparison of two professional groups. J Public Health 1997; 19: 295-300

4 Caplan RP. Stress, anxiety, and depression in hospital consultants, general practitioners, and senior health service managers. BMJ 1994; 309: 1261-3.

5 Chambers R, Belcher J. Comparison of the health and lifestyle of general practitioners and teachers. Br J Gen Pract 1993; 43: 378-82.

6 Department of Health. Mental Health and III Health in Doctors. Department of Health, 2008.

7 Johnson S, Cooper C, Cartwright S, Donald I, Taylor P, Millet C. The experience of work-related stress across occupations. J Manag Psychol 2005 20: $178-87$

8 Health and Safety Executive. Work Related Stress, Anxiety and Depression Statistics in Great Britain. Health and Safety Executive, 2015 (http:// www.hse.gov.uk/statistics/causdis/stress/stress.pdf).

9 Kivimaki M, Sutinen R, Elovainio M, Vahterad J, Räsänend K, Töyryd S, et al Sickness absence in hospital physicians: 2 year follow up study on determinants. Occup Environ Med 2001; 58: 361-6.

10 Siegrist J, Shackelton R, Link C, Marceau L, von dem Knesebeck O, McKinlay J. Work stress of primary care physicians in the US, UK and German health care systems. Soc Sci Med 2010; 71: 298-304.

11 Ramirez AJ, Graham J, Richards MA, Cull A, Gregory W. Mental health of hospital consultants: the effects of stress and satisfaction at work. Lancet 1996; 347: 724-8.

12 Burbeck R, Coomber S, Robinson SM, Todd C. Occupational stress in consultants in accident and emergency medicine: a national survey of levels of stress at work. Emerg Med J 2002; 19: 234-8.

13 Agius RM, Blenkin H, Deary IJ, Zealley HE, Wood RA. Survey of perceived stress and work demands of consultant doctors. Occup Environ Med 1996; 53: 217-24.

14 Graham J, Ramirez AJ, Cull A, Finlay I, Hoy A, Richards MA. Job stress and satisfaction among palliative physicians. Palliat Med 1996; 10: 185-94.

15 Brooks SK, Gerada C, Chalder T. Review of literature on the mental health of doctors: are specialist services needed? J Ment Health 2011; 20: 146-56.

16 Tomioka K, Morita N, Saeki K, Okamoto N, Kurumatani N. Working hours, occupational stress and depression among physicians. Occup Med 2011; 61 163-70.

17 Taylor C, Graham J, Potts HW, Richards MA, Ramirez AJ. Changes in menta health of UK hospital consultants since the mid-1990s. Lancet 2005; 366 : 742-4.

18 Carder M, McNamee R, Turner S, Hodgson JT, Holland F, Agius RM. Time trends in the incidence of work-related mental ill health and musculoskeletal disorders in the UK. Occup Environ Med 2013; 70: 317-24.
19 Centre for Occupational and Environmental Health. The Health and Occupational Research (THOR) Network. COEH, 2016 (http://www.populationhealth.manchester.ac.uk/epidemiology/COEH/research/thor/).

20 Carder M, Money A, Turner S, Agius RM. Workforce coverage by GB occupational physicians and disease incidence rates. Occup Med 2014; 64 271-8.

21 Carder M, McNamee R, Turner S, Hussey L, Money A, Agius R. Improving estimates of specialist-diagnosed, work-related respiratory and skin disease. Occup Med 2011; 61: 33-9.

22 Office for National Statistics. Standard Occupation Classification (SOC 2000). ONS, 2015 (http://www.ons.gov.uk/ons/guide-method/classifications/ archived-standard-classifications/standard-occupational-classification-2000/ index.html).

23 Office for National Statistics. Labour Force Survey. ONS, 2015 (http:// www.ons.gov.uk/ons/guide-method/method-quality/specific/labour-market/ labour-market-statistics/index.html).

24 Office for National Statistics. Standard Industrial Classification 2003 and 2007. ONS, 2016 (http://www.ons.gov.uk/ons/guide-method/classifications/ archived-standard-classifications/uk-standard-industrial-classification1992-sic92-/index.html).

25 Wolter K. Introduction to Variance Estimation (2nd edn). Springer, 2007.

26 McNamee R, Carder M, Chen $Y$, Agius R. Measurement of trends in incidence of work-related skin and respiratory diseases, UK 1996-2005. Occup Environ Med 2008; 65: 808-14.

27 Rich A, Viney R, Needleman S, Griffin A, Woolf K. 'You can't be a person and a doctor': the work-life balance of doctors in training - a qualitative study. BMJ Open 2016; 6: e013897.

28 Harvey SB, Modini M, Joyce S, Milligan-Saville JS, Tan L, Mykletun A, et al. Can work make you mentally ill? A systematic meta-review of work-related risk factors for common mental health problems. Occup Environ Med 2017; 74: $301-310$.

29 Firth-Cozens J. A perspective on stress and depression. In Understanding Doctor's Performance (eds JKJ Cox, A Hutchinson, P McAvoy): 22-37. Radcliffe Publishing, 2006.

30 Firth-Cozens J. Source of stress in women junior house officers. BMJ 1990; 301: 89-91.

31 Firth-Cozens J, Greenhalgh J. Doctors' perceptions of the links between stress and lowered clinical care. Soc Sci Med 1997; 44: 1017-22.

32 Taylor C, Graham J, Potts H, Candy J, Richards M, Ramirez A. Impact of hospital consultants' poor mental health on patient care. Br J Psychiatry 2007: 190: 268-9.

33 Harrison J. Illness in doctors and dentists and their fitness for work - are the cobbler's children getting their shoes at last? Occup Med 2006; 56: 75-6.

34 Chew-Graham CA, Rogers A, Yassin N. "I wouldn't want it on my CV or their records": medical students' experiences of help-seeking for mental health problems. Med Educ 2003; 37: 873-80.

35 Adams EF, Lee AJ, Pritchard CW, White RJ. What stops us from healing the healers: a survey of help-seeking behaviour, stigmatisation and depression within the medical profession. Int J Soc Psychiatry 2009; 56: 359-70.

36 Hassan TM, Ahmed SO, White AC, Galbraith N. A postal survey of doctors attitudes to becoming mentally ill. Clin Med 2009; 9: 327-32.

37 Hignett S, Fray M, Rossi MA, Tamminen-Peter L, Hermann S, Lomi, et al Implementation of the manual handling directive in the healthcare industry in the European Union for patient handling tasks. Int J Ind Ergonom 2007; 37: $415-23$.

38. Agius RM, Bonneterre V. What do surveillance schemes tell us about the epidemiology of occupational diseases? In Current Topics in Occupational Epidemiology (ed K Venables): 131-41. Oxford University Press, 2013.

39 UK Statistics Authority. Statistics on Health and Safety at Work. UK Statistics Authority, 2013 (https://www.statisticsauthority.gov.uk/wp-content/uploads/ 2015/12/images-assessmentreport261statisticsonhealthandsafetyatwor_ tcm97-43346.pdf)

40 McNamee R, Chen $Y$, Hussey L, Agius R. Time-sampled versus continuoustime reporting for measuring incidence. Epidemiology 2010; 21: 376-8. 